\title{
The Occupation Ability Training Strategies of Students Majoring in Preschool Education
}

\author{
Ren Chaoke \\ Langfang Teachers University, Langfang City, Hebei Province, 065000 \\ 346591653@163.com
}

\section{Keywords: Preschool Education; Students' Occupational Ability; Training}

\begin{abstract}
: the occupational ability is significant for students majoring in preschool education as well as critical basis to assess whether the graduates majoring in high vocational preschool education are qualified or not.A variety of activities shall be held to stimulate students' occupational affection, for example,occupational knowledge shall be obtained through knowledge teaching,internship and other activities and vocational skills should be improved through team training and multi-position internship so that students will be of comprehensive vocational abilities and potentials for professional development.
\end{abstract}

\section{Introduction}

Quality requirements for personnel working for preschool education have become higher and higher under the condition of continuous reform of preschool education. In spite of the fact that achievements has been reached in education reforms, while occupational training for students shall be reformed continuously to adapt development of the society. Training for occupational abilities majoring in preschool education shall be premised on recognition of their own majors, based on familiarization of their working environment and rooted in practical teaching. Therefore, occupational ability training for students majoring in preschool education should not be single training on teaching skills but also training for occupational affection,should be not only learning from the books, but also ability to control the scene in class and should not only require ability in examination, but also be tested by practical teaching.

\section{Training for Occupational Affection}

The basic power for development of teachers is occupational affection and spirit of teachers. The premises for occupational ability of preschool education majors is cultivation for occupational affection and professional strengthening of the professional identification. The cultivation of professional affection is subject to a number of factors. The first factor is the interest of the occupation itself, which is related to the personalities of the students, for example,some student really enjoy playing with kids while some others will feel uncomfortable when playing with kids. This factor will influence the students from the origin and will decide whether the students could learn professional knowledge hardly and pursue teaching improvement positively when they have started working. The second factor is the status of preschool teaching. At the very moment of social development, reputation and reward of the industry still play a most important role in people's 
employment choice. Preschool teachers have been considered to be baby sisters for a long time and their work have nothing to do with science and profession. What's more, the payment for preschool teachers is relatively low and these adverse external factors have also blocked people's identification and selection of the occupation.

To cultivate students' professional affection, the activity of making friends, full of joy and happiness, shall be arranged by the school at the beginning to help students to be familiar with the preschool teaching environment, experience occupational affection and understand the spirit of the occupation. The so-called "making friends" is to make students to conduct all kinds of activities with kids in the training center of affiliated kindergarten that students should conduct varieties of activities with kids appointed to him or her for one and a half day in a fixed time. Activities shall initiate with free talk, telling stories and develop into assisting teachers in kindergarten carry out a variety of large games and outdoor activities. These activities will contribute to inspire students' affection to kids to raise the recognition to their major and enhance the interest and enthusiasm to teaching.

Secondly, opportunities of the social transformation and the fact that our country is attaching great importance to preschool education shall be made full use of and professional propaganda in preschool education shall be performed. On the one hand, the propaganda shall inform the students the current social status, reputation and payment change of preschool education to the students to stimulate their enthusiasm in preschool education; On the other hand, propaganda shall highlight the profession and science of preschool education to make students understand the uniqueness and necessity of their majors and help them to establish scientific and reasonable understanding to their majors. In a word, affection stimulation and professional identification are basic to stimulation of occupational affection of the students and only when they can be done well that students' occupational affection can be truly implemented.

\section{Learning for Occupational Knowledge}

Knowledge learning is basic to ability development. Modern psychology has divided knowledge into declarative knowledge and procedural knowledge. As for occupation knowledge of preschool education, declarative knowledge is mainly obtained through reading,examination and other methods, while to acquire procedural knowledge, students are required to is required to converse declarative knowledge in practice, put their observations into practice and practice in person. Therefore,the school with preschool education major shall emphasize the learning of declarative knowledge and procedural knowledge to lay a good foundation for students' occupational ability improvement.

Firstly, the school should attach great importance to learning of declarative knowledge by making good curriculum and paying more attention to teaching, learning and self learning and ensuring time and space for students to learn. The school should stimulate students enthusiasm to learn professional knowledge of preschool education and help the students to grasp the basic concepts and the laws of the major to lay a good foundation for the students to form scientific concept of education and perform their responsibility scientifically after working.

Secondly, schools should create good conditions for students to learn procedural knowledge. 
Procedural knowledge is about "how to do", which has the same meaning and extension with the popular concept of "skill". Vocational ability development of students is directly related to acquirement of program knowledge. Therefore, students must attach great importance to program knowledge. Schools should arrange all kinds of internship and demonstration activities to prepare students for future occupational practice.Specifically, schools can arrange students to kindergarten to observe and simulate teaching.

Although internship is not direct practice of preschool education, it will help to students to integrate theory with practice, understand and get familiar with the activities of preschool education, enhance student's perceptual knowledge of preschool education, enhance the students' affection to preschool education and understanding to professional theory and help students to gradually enhance observation, evaluation, reflection and other education skills to accumulate teaching experience for the students when working.[3] Internship of students need the joint guidance of school teachers and kindergarten teachers and training project theory shall be designed by both of them, making efforts to cover children's behavior, teaching behavior of the teachers, teaching activities in kindergarten observation of creation of kindergarten environment, recording, evaluation and other aspects. After the kids leave the kindergarten,feedback shall be obtained through observation and research of teaching, case discussion, observation report, investigation report and education notes and teachers shall give timely guidance, help and summary and make it an important part of students' professional course to improve the effectiveness of the students' internship.

Simulation teaching,as a practical, dynamic, interactive and collaborative teaching method, should be set throughout the professional learning of all grades and be guided by the double qualified teachers. Generally,simulation teaching shall be performed in team teaching, which posses not only simulation teaching but also the case analysis and comment on the scene from the teachers. With the application of simulation teaching, it will effectively widen the view of teaching theory, shorten the distance between theory and practice of education and train the future teachers with practical skills, to enable students to overcome tension, panic in the process of teaching and get used to the position of a teacher as soon as possible.

\section{Practice of Occupational Skills}

To achieve the purpose of final occupational ability and comprehensive ability confirmed through the training program of the preschool education, it is far more enough to only posses professional affection and learning of professional knowledge. At present, preschool education majors of general high vocational colleges are applied discipline basically speaking and practice ability and operation ability are essential after they have received the professional education and also important embodiment of professional ability. [4] Training and internship are the most effective ways to develop students' ability of practice and operation.

Training in Team Project. Training in team project is to solve the practical problems in the filed to develop students occupational ability, when proposals for typical task in the field and problems in practice will be proposed and put into practice.The whole process will be guided by specialized course teachers and kindergarten teachers and under the guidance of collaboration students. The model is based on practice in kindergarten and have the characteristics of operation and research, 
authenticity, pertinence, flexibility, normative and comprehensive characters.

First of all, the team project shall be performed in group, basically three persons in a group, when expertise complementary in advantages and disadvantages shall be taken into consideration, forming ladder type distribution, which will stimulate and help training for students naturally and cultivate the spirit of teamwork.

Secondly, students will face the real occupation work situation and typical working task, such as conservation activities, environment creation, game activities, education and teaching activities, activities in the field of education design, implementation and evaluation of problems and home work etc, which can involve all aspects in preschool education, forming professional ability training rise in step,when students are required to perform positive and creative research and comprehensive practice with what they have learned. Prior to the training, students are required to hand in their own plan or scheme, which will be analyzed and the best one will be chosen by the guide teacher and the person who is in charge of the group shall lead and practice the plan comprehensively. In the process of the plan, students should reflect and and improve with educational wisdom in accordance with the scene in reality.

To train the students in team project, it will decompose the knowledge structure and ability training that the occupation or group needs by layers and adopt the organization structure of kindergarten teaching to stimulate the initiative and creativity of students in training and strengthen the effectiveness and capabilities of the students' professional ability cultivation in step.

Internship in Different Posts. In order to make the students professional and potential talents who are capable of working once in the position, can be transferred to another position at once, the school shall change the traditional preschool education practice, especially the internship arrangement of only being a teacher in kindergarten, but require the students to attend all kinds of training, such as nurse,nursery teacher,preschool education for 0-3years old kids and art, language, dance and management of preschool education in all kinds of preschool training centers under the principle of enhancing internship of a teacher in kindergarten through occupational training activities of whole process, in step and no distance with the real occupation. The training activities of preschool education in multiple positions can effectively realize the purpose of making students to adapt to the first position when working, be transferred to another post at once and sustainable development.

\section{Conclusion}

It will effectively realize the objectives of preschool education majors, shorten the adaptive period for graduates and improve students' competitive ability in the talents market. It is complicated and systematic project to train and asses occupational skills and with the deepening of educational reform and higher requirement of the society, all teachers shall practice, explore and improve that with practical attitude so that occupational training system of preschool education characters can be established.

\section{Reference}


[1] Jiang Lili. Practice and Analysis on Occupational Ability Training for Preschool Education Majors in High Vocational College., 2009,02:76-77.

[2] Zhang Jianbo. Brief Analysis on Occupational Skill Training for Preschool Education Students[J]. Theory Observation, 2006,02:125-126.

[3] Wei Shengxia. Brief Analysis on Occupation Ability Training for Preschool Education Students in Secondary Vocational College [J]. Secondary Vocational Education, 2012,04:10-12.

[4] Wang Yan. Study on Occupational Ability Training for Preschool Education Students in High Normal Colleges[J] Journal of Hubei Correspondence University, 2012,10:19-20.

[5] Huo Qiao Lian. Construction and Reflection on Occupational Ability Training of Preschool Education in Colleges [J]. Education and Occupation,2013,18:103-105. 